\title{
Radionuclide transfer to fruit in the IAEA TRS No. 472
}

\author{
F. Carini ${ }^{1}$, M. Pellizzoni ${ }^{1 *}$ and S. Giosuì ${ }^{2}$ \\ ${ }^{1}$ Institute of Agricultural and Environmental Chemistry \\ Università Cattolica del Sacro Cuore - Via Emilia Parmense, 84 \\ Piacenza, Italy \\ 2 Institute of Entomology and Vegetable Pathology \\ Università Cattolica del Sacro Cuore - Via Emilia Parmense, 84 \\ Piacenza, Italy
}

\begin{abstract}
This paper describes the approach taken to present the information on fruits in the IAEA report TRS No. 472, supported by the IAEATECDOC-1616, which describes the key transfer processes, concepts and conceptual models regarded as important for dose assessment, as well as relevant parameters for modelling radionuclide transfer in fruits. Information relate to fruit plants grown in agricultural ecosystems of temperate regions. The relative significance of each pathway after release of radionuclides depends upon the radionuclide, the kind of crop, the stage of plant development and the season at time of deposition. Fruit intended as a component of the human diet is borne by plants that are heterogeneous in habits, and morphological and physiological traits. Information on radionuclides in fruit systems has therefore been rationalised by characterising plants in three groups: woody trees, shrubs, and herbaceous plants. Parameter values have been collected from open literature, conference proceedings, institutional reports, books and international databases. Data on root uptake are reported as transfer factor values related to fresh weight, being consumption data for fruits usually given in fresh weight.
\end{abstract}

*E-mail: franca.carini@unicatt.it

This is an Open Access article distributed under the terms of the Creative Commons Attribution License 2.0, which permits unrestricted use, distribution, and reproduction in any medium, provided the original work is properly cited. 


\section{Introduction}

The Technical Report Series (TRS) No. 472 "Handbook of Parameter Values for the Prediction of Radionuclide Transfer in Terrestrial and Freshwater Environments" [1] derives from the TRS 364 Revision carried out within the framework of the IAEA International EMRAS (Environmental Modelling for Radiation Safety) Programme, Working Group 1 of Theme 1, in the years 2003-2007 [2].

At the time of the drawing up of the TRS 364 "Handbook of parameter values for the prediction of radionuclide transfer in temperate environments" [3], edible crops had been divided into seven groups: cereals, fodder, grass, pods, root crops, tubers and vegetables. Such a division reflected the criteria used in modelling approaches [4], and was imposed by the data available at that time. Even the processes described to model the transfer to edible crops took into account plants such as grass, vegetables and cereals. Various experimental studies on the behaviour of radionuclides in fruit systems had been carried out, but the information was not sufficient to be rationalized [5]. The only parameter on fruits quoted in the TRS 364 was the soil-to-plant transfer factor for $\mathrm{Sr}[6]$.

The consequences on food items of the Chernobyl event pointed out the peculiarity of the behaviour of radionuclides in some crops. After the recognition of the potential radiological significance of fruit, a Fruits Working Group carried out experimental and modelling activities in the years 19972000 as part of the IAEA International BIOMASS (BIOsphere Modelling and ASSessment) Programme [7]. The results of the activities of the group, were summarized both in the Special Issue of the Journal of Environmental Radioactivity "Radionuclide Transfer to Fruits" published in 2001, and in the Special Issue devoted to the BIOMASS Programme published in 2005. Both publications have provided a large share of the information utilized for the topic of the TRS 364 Revision on the transfer to fruit.

This paper summarizes the key transfer processes concerning the behaviour of radionuclides in fruits, and the soil to fruit transfer factors related to fruit plants grown in agricultural ecosystems of temperate regions.

\section{Key transfer processes in fruits}

Fruit contamination following a release to atmosphere can be the result of various processes: (i) direct deposition to exposed fruit surfaces, absorption by the fruit skin and transport to the interior; (ii) deposition to exposed 
plant surfaces (directly from the atmosphere or as a result of resuspension), absorption to interior and translocation to fruit; (iii) for perennial plants: remobilisation of radionuclides from the leaves to the over-wintering organs prior to leaf drop, followed by retranslocation from storage organs to other plant components at the resumption of growth; (iv) deposition to soil, vertical migration in the soil profile, root uptake and transfer to the fruit. The main processes involved in the transfer of radionuclides to fruits are shown in fig. $1[8]$.

The relative significance of each pathway after release of radionuclides depends upon the radionuclide, the kind of crop, the stage of plant development and the season at time of deposition. Furthermore, in agricultural ecosystems, the transfer of radionuclides to fruit is generally affected by human intervention, which includes horticultural practices, intended to modify physiology and translocation of nutrients, to achieve early cropping, high, early and sustained yield, and high fruit quality. The published literature that describes the phenological development of above- and below-ground organs of temperate tree fruit, and hence the potential for uptake of radionuclides directly from the atmosphere and via the soil, has been reviewed by Atkinson and Webster [9].

For the information related to the deposition on the aboveground part of the plant, the reader is referred to TECDOC 1616 [10] and Carini and Bengtsson [11].

\section{Remobilisation in perennial plants}

Generally speaking, when the scenario is a single deposition event, the residual activity in the plant in the years following deposition is regarded as deriving from soil as the donor compartment, through the processes of soil to plant transfer and/or resuspension and splash. Although this may hold true for annual plants, it is not always so for perennial plants such as fruit trees. A fraction of the radionuclides intercepted by, and absorbed into, the leaves in the year of deposition is remobilised and translocated to the storage organs, mainly wood and roots, before leaf drop. Remobilisation is highly selective for mineral elements and depends on their concentration in the fully expanded leaves. At the resumption of growth, a portion of the plant reservoir can be remobilised from the inventory of the plant to fruits, leaves and shoots. This process is assumed to be responsible for residual fruit contamination in perennial fruit trees in the first few years after contamination, a hypothesis supported by data from various authors [12-16]. Therefore, the 


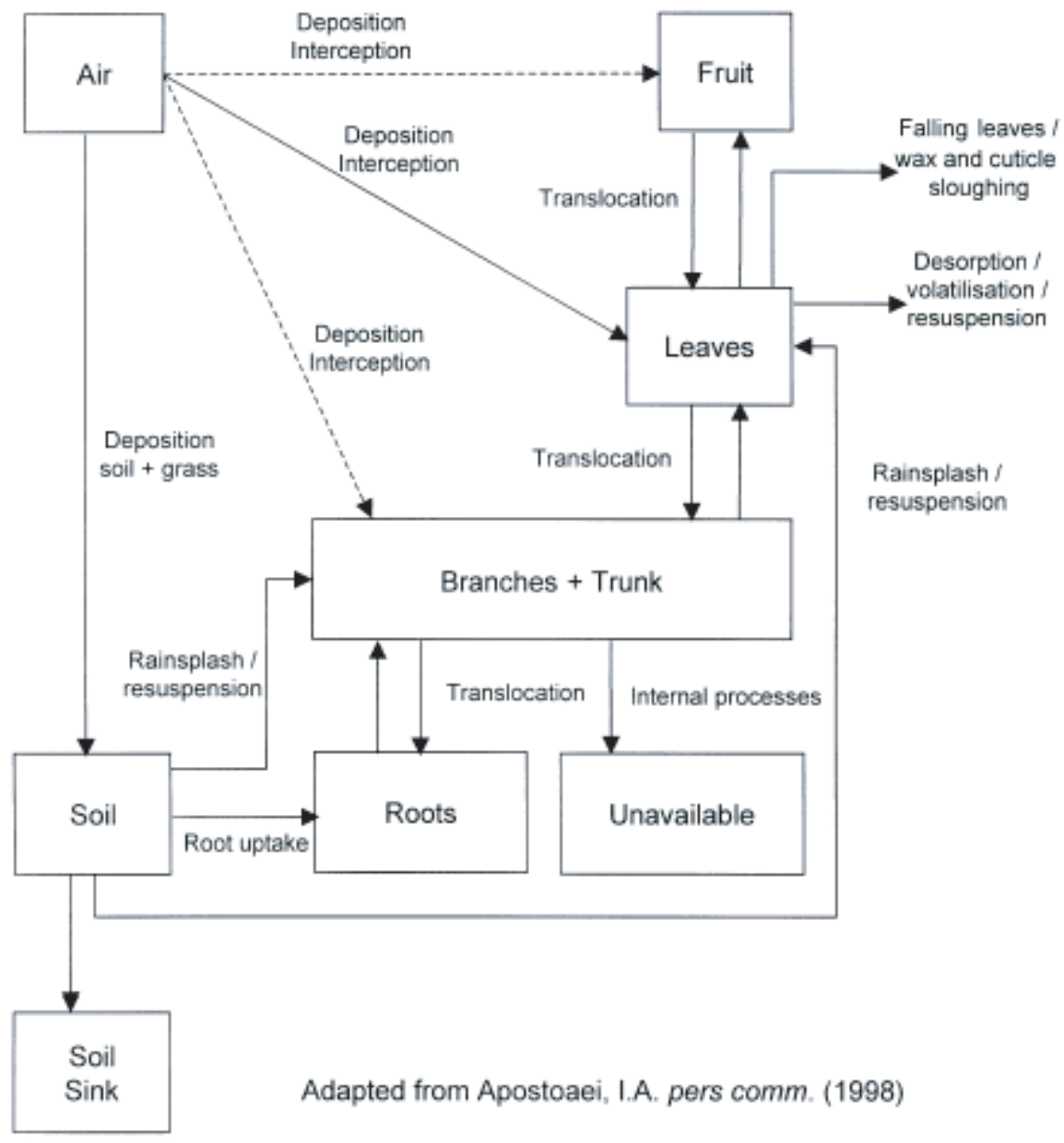

Figure 1: Processes involved in the transfer of radionuclides to fruit. From Mitchell [8]. 
components involved in the contamination of fruit in the years following a single, acute deposition are both the soil reservoir and the plant reservoir. The relative importance of these reservoirs will change with time. However, their respective contributions have not yet been clearly defined.

\section{Root uptake}

The different migration of radionuclides in the soil profile represents a different potential source of contamination for plants with different root penetration in soil. Data on root uptake have been collected from open literature, conference proceedings, institutional reports, books and international databases. Given the scarce information available on the subject, the choice has been made to not reject any information. More details on the information sources are reported in Carini [17].

Data on root uptake are reported as $F_{v}$ values related to fresh weight, because consumption data for fruits are usually given in fresh weight:

$$
F_{v}=(\mathrm{Bq} \text { per fresh fruit weight }) /(\mathrm{Bq} \text { per dry soil weight })
$$

A summary of the $F_{v}$ given in the TRS 472 is shown in table I. Estimations of the transfer parameter values and the extent of uncertainty about each such value were carried out by applying a statistical analysis, where possible. In the ideal case, where three or more values were available $(N>2)$, a geometric mean was given in the tables as the mean value. The uncertainties assigned to the geometric mean were estimated by using the geometric standard deviation. If only two values were available, the parameters were shown in reported ranges with minimum and maximum values, along with the arithmetic mean and the standard deviation. Thus, depending on the number of values used for the statistical analysis, the mean given in table I may be a geometric mean or an arithmetic mean, with the corresponding uncertainties. The number of data $N$ is also reported. In some cases, the values were given without a statement of uncertainty or a range, because of the limited data available. The values in such cases should be used with a great caution in assessment previsions.

$F_{v}$ values for caesium cover two orders of magnitude, from $10^{-4}$ to $10^{-2}$. The variability in $F_{v}$ values reflects primarily differences in soil characteristics rather than differences among plants. The highest values are for light textured or organic soils. $F_{v}$ values for strontium are generally one order of magnitude higher than for caesium, ranging from $10^{-3}$ to $10^{-1}$. 
Table I: Soil to fruit transfer factors $\left(F_{v}\right)$ for $\mathrm{Cs}, \mathrm{Sr}, \mathrm{Pu}, \mathrm{Am}$ and I.

\begin{tabular}{|c|c|c|c|c|c|c|c|c|}
\hline Radionuclide & $\begin{array}{l}\text { Plant } \\
\text { group }\end{array}$ & $N$ & $\begin{array}{l}\text { Arith } \\
\text { mean }\end{array}$ & $\mathrm{SD}$ & $\begin{array}{l}\text { Geom. } \\
\text { mean }\end{array}$ & GSD & Min & $\operatorname{Max}$ \\
\hline \multirow[t]{3}{*}{ Cs } & $\begin{array}{l}\text { Woody } \\
\text { trees }\end{array}$ & 15 & $1.510^{-2}$ & $2.210^{-2}$ & $5.810^{-3}$ & 1.5 & $8.610^{-4}$ & $8.010^{-2}$ \\
\hline & Shrubs & 6 & $2.610^{-3}$ & $1.910^{-3}$ & $2.110^{-3}$ & $8.110^{-1}$ & $6.910^{-4}$ & $5.710^{-3}$ \\
\hline & $\begin{array}{l}\text { Herbaceous } \\
\text { plants }\end{array}$ & 8 & $2.910^{-3}$ & $3.310^{-3}$ & $1.510^{-3}$ & 1.2 & $4.110^{-4}$ & $8.910^{-3}$ \\
\hline \multirow[t]{3}{*}{$\mathrm{Sr}$} & $\begin{array}{l}\text { Woody } \\
\text { trees }\end{array}$ & 18 & $2.510^{-2}$ & $1.910^{-2}$ & $1.710^{-2}$ & $9.710^{-1}$ & $1.210^{-3}$ & $7.010^{-2}$ \\
\hline & Shrubs & 9 & $5.510^{-2}$ & $3.710^{-2}$ & $4.410^{-2}$ & $7.610^{-1}$ & $1.410^{-2}$ & $1.110^{-1}$ \\
\hline & $\begin{array}{l}\text { Herbaceous } \\
\text { plants }\end{array}$ & 8 & $5.510^{-2}$ & $6.910^{-2}$ & $3.310^{-2}$ & $1.010^{\circ}$ & $1.210^{-2}$ & $2.110^{-1}$ \\
\hline \multirow[t]{3}{*}{$\mathrm{Pu}$} & $\begin{array}{l}\text { Woody } \\
\text { trees }\end{array}$ & 10 & $2.610^{-3}$ & $6.610^{-3}$ & $1.410^{-4}$ & $2.910^{\circ}$ & $1.310^{-6}$ & $2.110^{-2}$ \\
\hline & Shrubs & 2 & $1.710^{-4}$ & $1.510^{-4}$ & $1.310^{-4}$ & $1.010^{\circ}$ & $6.410^{-5}$ & $2.710^{-4}$ \\
\hline & $\begin{array}{l}\text { Herbaceous } \\
\text { plants }\end{array}$ & 9 & $2.410^{-4}$ & $3.110^{-4}$ & $1.210^{-4}$ & $1.210^{\circ}$ & $2.710^{-5}$ & $8.310^{-4}$ \\
\hline \multirow[t]{3}{*}{$\mathrm{Am}$} & $\begin{array}{l}\text { Woody } \\
\text { trees }\end{array}$ & 6 & $1.810^{-4}$ & $2.710^{-4}$ & $3.110^{-5}$ & $2.410^{0}$ & $1.310^{-6}$ & $6.210^{-4}$ \\
\hline & Shrubs & 2 & $1.510^{-4}$ & $1.210^{-4}$ & $1.210^{-4}$ & $8.910^{-1}$ & $6.510^{-5}$ & $2.310^{-4}$ \\
\hline & $\begin{array}{l}\text { Herbaceous } \\
\text { plants }\end{array}$ & 8 & $1.810^{-4}$ & $2.310^{-4}$ & $1.110^{-4}$ & $1.010^{\circ}$ & $4.110^{-5}$ & $7.210^{-4}$ \\
\hline \multirow[t]{2}{*}{ I } & $\begin{array}{l}\text { Woody } \\
\text { trees }\end{array}$ & 5 & $1.210^{-2}$ & $1.210^{-2}$ & $6.310^{-3}$ & $1.610^{0}$ & $4.110^{-4}$ & $3.110^{-2}$ \\
\hline & $\begin{array}{l}\text { Herbaceous } \\
\text { plants }\end{array}$ & 1 & $1.510^{-2}$ & & & & & \\
\hline
\end{tabular}


Similarly to caesium, soil characteristics are fundamental in determining the amount of strontium transferred from soil to fruit: uptake from organic soil is one order of magnitude less than that from loam and sand. There is also some evidence that the genotype of a plant has a weight similar to soil characteristics in determining the uptake of radiostrontium: strawberry and blackcurrant show the highest $F_{v}$ values, in the order of $10^{-1}$, whereas there are small differences between values for the other fruits [17].

Plutonium and americium appear to behave in a similar way in the soilplant system and $F_{v}$ values, $10^{-6}$ to $10^{-4}$, follow approximately the same trend for each class of fruit. Data on $F_{v}$ for iodine are scarce and show a range from $10^{-4}$ to $10^{-2}$. Some of the data in the literature have been obtained from weapons fallout in field conditions. $F_{v}$ values for cerium and curium are all in the order of $10^{-4}$, whereas those for ruthenium range from $10^{-4}$ to $10^{-3}$.

\section{Some recommendations for research and modelling}

Some of the information sources used in this review are for the temperate climate of Northern Europe, a relatively minor fruit-producing area. Large quantities of fruit and related products may be imported. It is important to take the contribution of imported fruit into account when considering the radiation exposure of a population due to contaminated fruit. It is also important that consideration should be given to the full range of fruits grown in all countries; in particular, grapes, olives, citrus fruits and bananas.

The information on radionuclides in fruits is mainly about acute releases of radioactivity, while there is a lack of information of data for continuous releases. Notwithstanding this, modelling activities carried out under the IAEA BIOMASS Programme revealed a greater degree of consistency for continuous rather than for acute deposition scenarios, probably due to the exclusion from continuous deposition models of those short-term processes greatly affecting the radionuclide concentration in fruit.

There is a need to standardise the methodology of carrying out experiments on foliar uptake and to standardise the mathematical description of the processes. There is a need for research on the behaviour of radionuclides in fruit crops to drive model development, not simply to parameterise existing models. Research should focus on understanding the key processes.

In addition, the age and growth stage of fruit at the time of contamination is an important factor in modelling the transfer of radionuclides to 
fruit. Furthermore, there is a need to compile a database of growth details for important fruit. The database should include leaf area index and herbage density over a growing season and soil type and climatic region. There are specific needs for data on shrub-type fruits, and for research on the deposition and transfer of ${ }^{129} \mathrm{I}$ to food crops, including fruits.

Future work has to be focused on the aim of producing information useful for evaluation of radiation doses to humans. This means addressing the key issues of: (i) which are the most important processes and how should these be represented? (ii) Which classes of plants and/or which species have the highest or lowest transfer factors for a given radionuclide?

\section{Acknowledgments}

This work was supported by the IAEA, Vienna, and by the MIUR, Italy under the project PRIN 2007NKX4B8_002. The work reported here is the result of the work carried out by many experts in the IAEA BIOMASS Fruits Working Group.

\section{References}

[1] International Atomic Energy Agency, tRS No. 472 (IAEA, Vienna) 2010.

[2] Calmon Ph., Fesenko S., Voigt G. and Linsley G., J. Environ. Radioactiv., 100 (2009) 671.

[3] International Atomic Energy Agency, TRS No. 364 (IAEA, Vienna) 1994.

[4] International Atomic Energy Agency, Safety Series No. $5 \%$. (IAEA, Vienna) 1982.

[5] Carini F., J. Environ. Radioactiv., 46 (1999) 77.

[6] Frissel M. J., Eight Report of the IUR W.G. on Soil-to-Plant Transfer (IUR, Balen, Belgium) 1992.

[7] Carini F. et al., J. Environ. Radioactiv., 84 (2005) 271.

[8] Mitchell N. G., J. Environ. Radioactiv., 52 (2001) 291. 
[9] Atkinson C. J. and Webster A. D., J. Environ. Radioactiv., 52 (2001) 131.

[10] International Atomic Energy Agency, teCDOC No. 1616 (IAEA, Vienna) 2009.

[11] Carini F. and Bengtsson G., J. Environ. Radioactiv., 52 (2001) 215.

[12] Baldini E., Bettoli M. G. and Tubertini O. Advances in Horticultural Science 1 (1987) 77.

[13] Antonopoulos-Domis M., Clouvas A., Tervisidis F. and Gagianas A., Proc. of an International Conference organized by the Spanish Nuclear Society and cosponsored by the European Nuclear Society (Barcelona, 1988) 503.

[14] Antonopoulos-Domis M., Clouvas A. and Gagianas A., Health Phys. 58 (1990) 737.

[15] Antonopoulos-Domis M., Clouvas A. and Gagianas A., Health Phys. 61 (1991) 837.

[16] Frissel M. J., Proc. of the XXVII annual meeting of ESNA, WG 3, edited by MH. Gerzabek, Vienna (1997) 189.

[17] Carini F., J. Environ. Radioactiv., 52 (2001) 237. 